\title{
Facile isothermal solid acid catalyzed ionic liquid pretreatments to enhance the combined sugars production from Arundo donax Linn.
}

\author{
Tingting You, Lupeng Shao, Ruizhen Wang, Liming Zhang and Feng $\mathrm{Xu}^{*}$
}

\begin{abstract}
Background: Solid acid catalyzed inexpensive ionic liquid (IL) pretreatment is promising because of its effectiveness at decreasing biomass recalcitrance to subsequent enzymatic hydrolysis or in situ hydrolysis of carbohydrate oligomers. However, the conventional strategy was limited by the complex non-isothermal process and considering only one aspect of sugar recovery. In this study, facile isothermal pretreatments using Amberlyst 35DRY catalyzed 1-n-butyl3-methylimidazolium chloride $\left(\left[\mathrm{C}_{4} \mathrm{mim}\right] \mathrm{Cl}\right)$ at mild conditions were developed on bioenergy crop Arundo donax Linn. to enhance the combined sugars released. The physicochemical differences, enzymatic digestibility, and sugars released in situ were evaluated and compared to define the best set of conditions.

Results: The optimized isothermal pretreatment $\left(110^{\circ} \mathrm{C}\right.$, IL for $3 \mathrm{~h}$, Amberlyst for $1 \mathrm{~h}$ ) resulted in significant enhancement in combined sugars released $(58.4 \mathrm{~g} / 100 \mathrm{~g}$ raw materials), recovering $85.0 \%$ of the total reducing glycan in the raw biomass. This remarkable improvement could be correlated to cellulose crystallinity reduction, crystalline conversion, and partial removal of the main chemical components caused by the pretreatment. Particularly, solubilization of hemicelluloses and partial depolymerization of cellulose contributed to the synergetic improvement of sugars production in enzymatic hydrolysis and in situ. Irrespective of the generous differences in mass recovery, the highest cellulose digestibility of $90.2 \%$ and sugar released of $43.0 \%$ (based on initial materials) in the pretreatment liquor were obtained. Interestingly, lignin (0.8-6.1\%) and sugars derived lactic acid (4.70-5.94\%) were produced without any notable deleterious effects.
\end{abstract}

Conclusions: Isothermal $\left[\mathrm{C}_{4} \mathrm{mim}\right] \mathrm{Cl}$-Amberlyst pretreatment was a highly effective, simple, and convenient process that produced high yields of fermentable sugars from recalcitrant biomass by in situ hydrolysis of soluble biomass and enhancement of cellulose digestibility of the regenerated biomass. Relatively high amount of new revenues beyond sugars of this pretreatment could promote the commercial viability.

Keywords: Arundo donax Linn., Acid enhanced ionic liquid pretreatment, Enzymatic hydrolysis, Total reducing sugars

\section{Background}

The world's ever-growing energy demands and concerns over the shortage of oil reserves accompanying with its detrimental effects on climate change have garnered interest in the research for alternative renewable sources

*Correspondence: xfx315@bjfu.edu.cn

Beijing Key Laboratory of Lignocellulosic Chemistry, Beijing Forestry University, Beijing 100083, China for the sustainable production of fuels and petroleum based products [1]. Dedicated bioenergy crops, such as switchgrass, miscanthus, and reed are renewable and present in great abundance that can be converted to transportation fuels and commodity chemicals [2, 3]. A perennial grass Arundo donax Linn. is a promising candidate when compared to other bioenergy crops because of its high biomass production, plant adaptability, and low input required for its cultivation [2]. Studies investigating 
the conversion of this biomass to fermentable sugars would bring economic and ecological benefits. Due to the naturally rigid and complex submicroscopic structure of plant, pretreatment is a pre-requisite step to modify the physical and chemical properties and to enhance enzymes accessibility to achieve high yields of fermentable sugars [4].

Ionic liquids (ILs) have held great promise as powerful green solvents for pretreatment and dissolution of biomass with improved yields of reducing sugars [5-9]. This process has certain advantages such as environmentally benign, feedstock agnostic, and short processing time demanded to convert pretreated biomass to high yields of fermentable sugars [5, 10-12]. However, the high cost of IL impedes the industrial investment of this technology. Up to now, combinatorial pretreatments involving ILs and other chemicals have been developed to cut down the high cost of ILs whist boosting the sugars production [13-15]. Among them, acid in inexpensive prototype 1-n-butyl-3-methylimidazolium chloride $\left(\left[\mathrm{C}_{4} \mathrm{mim}\right]\right.$ $\mathrm{Cl}$ ) pretreatments have been considered as cost-effective alternatives to the expensive IL to disrupt the physical and biochemical barriers for enzymatic hydrolysis [15]. In the earlier works, in situ hydrolysis of carbohydrate oligomers that dissolved in IL to monomers with acid catalysts was proposed [16, 17]. Nevertheless, there exists a void of explicit knowledge regarding the promotion to the combined sugars production by in situ hydrolysis of IL-soluble biomass and enhancement of cellulose digestibility of regenerated biomass after pretreatment across techniques. For instance, Sun and coworkers [17] have tended to focus only on the production and extraction of sugars produced in IL. The evaluation of the potential sugar production from regenerated solids was ignored after the pretreatment.

Maximizing valorization of lignocellulosic biomass can be achieved by neoteric methods using ILs and acid catalysts [18]. Fractionation of biomass with ionic liquid-acid systems to cellulose-rich fractions is believed to facilitate cellulose conversion [15]. Compared to the liquid acids, solid acids such as nafion, Amberlyst resins, and zeolites are less toxic, easy to recycle, and substantially mitigating the undesired degrading compounds in pretreatment liquors [19]. Moreover, a few compounds of commercial interest, such as phenolic acid and lactic acid can be directly accessible from biomass by using heterogeneous solid acid in ILs [20-22]. For instance, da Costa Lopes and coworkers [21] used acid resin Amberlite XAD-7 to extract phenolic compounds that dissolved after a complete fractionation of biomass by IL. In our previous research, a two-step solid acid catalyzed $\left[\mathrm{C}_{4} \mathrm{mim}\right] \mathrm{Cl}$ pretreatment has been developed to open the rigid structure of plants [23]. Accordingly, 5.21-fold enhancement of fermentable sugars yield from $A$. donax could be gained by enzymatic hydrolysis. More recently, new acidic ILs have been therefore designed to efficiently separate cellulose-rich fractions from lignocellulosic biomass to enhance the cellulose digestibility $[6,7,9]$.

However, there are still some limitations inherent for the practical application of IL-solid acid pretreatments despite satisfactory sugars yields have been obtained. The previous proposed procedures $[15,23]$ required a comparatively high temperature $\left(160{ }^{\circ} \mathrm{C}\right)$ in the first IL pretreated step, which was higher than the maximum operating temperatures of most resins. Therefore, additional cooling apparatus was demanded to cool down the system before adding any acid resins. The extra procedure makes the pretreatment more complex and poses pivotal equipment cost and energy challenge when considering as part of a practical, large-scale biomass pretreatment process. In addition, chloride based ILs were reported to show signs of decomposition at temperatures of $160{ }^{\circ} \mathrm{C}$ [24]. The high temperature used in the stateof-the-art methods might deteriorate ILs quality for reuse. Furthermore, the in situ sugars production directly during the pretreatment was out of consideration when evaluated the effectiveness of pretreatments. To advance the pretreatment technology, we describe a facile isothermal pretreatment that used Amberlyst 35DRY catalyzed $\left[\mathrm{C}_{4} \mathrm{mim}\right] \mathrm{Cl}$ to achieve high combined fermentable sugars yields from bioenergy crops $A$. donax at mild conditions. The effects of pretreatments on the chemical composition, cellulose digestibility, structural features, and reducing sugars released in pretreatment liquors were detected and compared to find out the optimal condition. Other value-added chemicals were observed as the new revenues beyond sugars. The in-depth knowledge of this approach will be beneficial for raising the profitability of the entire biorefinery.

\section{Results and discussion}

Biomass isothermal pretreatment and dry mass recovery

A facile isothermal protic acid resin catalyzed ionic liquid pretreatment was utilized to deconstruct $A$. donax cell wall. To define the best set of conditions for pretreatment, $A$. donax was processed using different pretreatment combination of temperature and acid reaction time and the yields of recovered samples are compared in Table 1.

Temperatures of $90-150{ }^{\circ} \mathrm{C}$ and acid reaction time intervals of $0.5-1.5 \mathrm{~h}$ (Table 1 ) were used to avoid the degradation of Amberlyst 35DRY while reducing biomass recalcitrance. As expected, the dry mass recovery decreased gradually with increasing temperature and prolonging acid reaction time, ranging from $95.4 \%$ for the R90-1 sample to 25.8 \% for the R150-0.5 sample. After 
Table 1 Mass recovery and crystallinity of the raw and pretreated $A$. donax under different conditions

\begin{tabular}{|c|c|c|c|c|c|}
\hline \multirow[t]{2}{*}{ Samples } & \multicolumn{2}{|c|}{ Pretreatment conditions } & \multirow[t]{2}{*}{ Recovered A. donax (\%) } & \multirow[t]{2}{*}{ Crl (\%) } & \multirow[t]{2}{*}{ LOI } \\
\hline & {$\left[\mathrm{C}_{4} \operatorname{mim}\right] \mathrm{Cl}$} & Amberlyst 35DRY & & & \\
\hline Raw & Untreated & Untreated & 100 & 36.0 & 1.43 \\
\hline R90-1.0 & $90^{\circ} \mathrm{C} 3 \mathrm{~h}$ & $90^{\circ} \mathrm{C} 1.0 \mathrm{~h}$ & 95.4 & 29.4 & 0.93 \\
\hline R100-1.0 & $100^{\circ} \mathrm{C} 3 \mathrm{~h}$ & $100^{\circ} \mathrm{C} 1.0 \mathrm{~h}$ & 78.4 & 31.4 & 0.58 \\
\hline R110-1.0 & $110^{\circ} \mathrm{C} 3 \mathrm{~h}$ & $110^{\circ} \mathrm{C} 1.0 \mathrm{~h}$ & 58.0 & 24.7 & 0.63 \\
\hline R120-0.5 & $120^{\circ} \mathrm{C} 3 \mathrm{~h}$ & $120^{\circ} \mathrm{C} 0.5 \mathrm{~h}$ & 66.1 & 23.2 & 0.53 \\
\hline R120-1.0 & $120^{\circ} \mathrm{C} 3 \mathrm{~h}$ & $120^{\circ} \mathrm{C} 1.0 \mathrm{~h}$ & 46.7 & 25.8 & 1.03 \\
\hline R120-1.5 & $120^{\circ} \mathrm{C} 3 \mathrm{~h}$ & $120^{\circ} \mathrm{C} 1.5 \mathrm{~h}$ & 31.7 & 27.3 & 0.56 \\
\hline R130-0.5 & $130^{\circ} \mathrm{C} 3 \mathrm{~h}$ & $130^{\circ} \mathrm{C} 0.5 \mathrm{~h}$ & 53.5 & 25.2 & 0.86 \\
\hline R140-0.5 & $140^{\circ} \mathrm{C} 3 \mathrm{~h}$ & $140^{\circ} \mathrm{C} 0.5 \mathrm{~h}$ & 28.2 & 25.8 & 1.15 \\
\hline R150-0.5 & $150^{\circ} \mathrm{C} 3 \mathrm{~h}$ & $150^{\circ} \mathrm{C} 0.5 \mathrm{~h}$ & 25.8 & 16.5 & 13.78 \\
\hline
\end{tabular}

pretreatment at $90{ }^{\circ} \mathrm{C}$ and Amberlyst catalyzed for $1.0 \mathrm{~h}$ (R90-1.0), only $4.6 \%$ biomass was consumed by the system, but more than $70 \%$ biomass was lost after pretreatment at $150{ }^{\circ} \mathrm{C}$ and acid catalyzed for $0.5 \mathrm{~h}$ (R150-0.5). It is probably the consequences of severe degradation of carbohydrates and partial removal of lignin by IL-acid at high temperatures. Moreover, the $A$. donax pretreated at high temperatures likely reacted with the ionic liquid and formed a highly viscous paste that could increase the mass loss. It is interesting to note that the mass loss of R130-0.5 sample is lower than that of R120-1.0 and R1201.5 samples. These values differed from those described in the literature by Trinh et al. [12], which indicated that the pretreatment of softwood at $130{ }^{\circ} \mathrm{C}$ in $\left[\mathrm{C}_{4} \mathrm{mim}\right] \mathrm{Cl}$ resulted in considerable decrease in the solid yields than that at $120{ }^{\circ} \mathrm{C}$. Rinaldi and coworkers $[16,25]$ reported that Amberlyst released hydronium ions $\left(\mathrm{H}_{3} \mathrm{O}^{+}\right)$in $\mathrm{IL}$ progressively to selectively cleave the longer cellulose chain and other soluble compounds to oligomers and sugars. Amberlyst reaction time was therefore suggested to be the main controlling factor at a high incubation temperature for mass recovery from $A$. donax.

\section{Chemical composition of pretreated Arundo donax}

Chemical composition determination is of vital importance to understand the biomass conversion. The chemical compositions of raw $A$. donax and of samples submitted to IL-Amberlyst pretreatments are illustrated in Table 2. As can be seen, the raw A. donax used in this study presents cellulose (44.59\%), hemicellulose $(17.15 \%)$, and lignin (20.54\%) composition similar to those reported in the literature for the same material, whose values vary from $29.2-42.15 \%$ for cellulose, 19.2-32 \% for hemicellulose and $19.20-24.3 \%$ for lignin $[2,26]$. Significant differences in chemical compositions were observed in the IL-Amberlyst pretreated samples.
Ionic liquid typically with 1,3-dialkylimidazolium cations can liquefy both lignin and polysaccharides in plant cell wall and then can be reprecipitated from solutions by adding anti-solvents, for examples, water and ethanol $[27,28]$. During the selective regeneration, the major cell wall components were partially separated. Table 2 shows that the isothermal $\left[\mathrm{C}_{4} \mathrm{mim}\right] \mathrm{Cl}$-Amberlyst pretreatments contributed to the removal of hemicellulose in $A$. donax. The hemicellulose percentage decreased with elevated temperature and prolonged time of acid reaction. R1400.5 sample displayed the lowest hemicellulose content of $8.60 \%(2.43 \%)$ after the isothermal IL-Amberlyst pretreatment at $140{ }^{\circ} \mathrm{C}$ and acid catalyzed for $0.5 \mathrm{~h}$. This is primarily because both the acid and ionic liquid pretreatment at a high temperature favor the solubilization and chemical degradation of hemicellulose [29]. In an earlier work, the effect of $\left[\mathrm{C}_{4} \mathrm{mim}\right] \mathrm{Cl}$-hydrochloric acid pretreatment on grass samples was investigated (5\% solid loading, at $160{ }^{\circ} \mathrm{C}$ for $1.5 \mathrm{~h}$ followed by $15 \mathrm{~min}$ aicdolysis by $4 \mathrm{M} \mathrm{HCl}$ ) [17]. They also reported that IL-acid pretreatment had a major effect on hemicellulose and a xylan content of $1.1 \%$ was reported for the solid residue. Moreover, the acetyl contents in the pretreated samples were slightly decreased (Table 2), which may facilitate the enzymatic hydrolysis.

Cellulose was more susceptible to the high pretreatment temperature and long acid reaction time. The isothermal pretreatments resulted in 1.88-38.5\% cellulose removal. Cellulose in the pretreated $A$. donax samples was gradually decreased with increasing pretreatment temperature and acid reaction time, reaching a minimum of $6.09 \%$ at $150{ }^{\circ} \mathrm{C}$, acid catalyzed for $0.5 \mathrm{~h}$. The noticeable degradation of cellulose may ascribe to severe cellulose depolymerization at high temperature in IL-acid system [25]. Irrespective of mass loss, the relative content of cellulose in samples considering the same acid reaction time 
Table 2 Chemical composition of the raw and pretreated $A$. donax obtained after isothermal $\left[\mathrm{C}_{4} \mathrm{mim}\right] \mathrm{Cl}$-Amberlyst 35DRY pretreatments

\begin{tabular}{lllllrl}
\hline Samples & Cellulose & Hemicelluloses & AlL & Ash & Acetyl \\
\hline Raw & $44.59(44.59)^{c}$ & $17.52(17.52)$ & $19.15(19.15)$ & $1.39(1.39)$ & $0.81(0.81)$ & $4.91(4.91)$ \\
R90-1.0 & $44.77(42.71)$ & $17.15(16.36)$ & $18.19(17.35)$ & $1.2(1.14)$ & $1.09(1.04)$ & $4.70(4.49)$ \\
R100-1.0 & $52.38(41.07)$ & $15.7(12.31)$ & $19.06(14.94)$ & $1.25(0.98)$ & $1.11(0.87)$ & $4.89(3.84)$ \\
R110-1.0 & $56.56(32.80)$ & $11.21(6.50)$ & $23.27(13.50)$ & $1.32(0.77)$ & $1.66(0.96)$ & $4.22(2.45)$ \\
R120-0.5 & $51.39(33.97)$ & $14.13(9.34)$ & $22.73(15.02)$ & $1.17(0.77)$ & $1.23(0.81)$ & $4.24(2.79)$ \\
R120-1.0 & $47.43(22.15)$ & $11.65(5.44)$ & $25.35(11.84)$ & $1.03(0.48)$ & $1.72(0.80)$ & $4.31(2.01)$ \\
R120-1.5 & $42.99(13.63)$ & $9.51(3.01)$ & $34.46(10.92)$ & $1.06(0.34)$ & $1.81(0.57)$ & $3.99(1.27)$ \\
R130-0.5 & $54.24(29.02)$ & $13.85(7.41)$ & $23.72(12.69)$ & $1.21(0.65)$ & $1.57(0.84)$ & $4.64(2.48)$ \\
R140-0.5 & $46.14(13.01)$ & $8.6(2.43)$ & $39.22(11.06)$ & $1.12(0.32)$ & $2.6(0.73)$ & $4.84(1.36)$ \\
R150-0.5 & $23.62(6.09)$ & $10.19(2.63)$ & $46.99(12.12)$ & $1.03(0.27)$ & $2.00(0.52)$ & $4.77(1.23)$ \\
\hline
\end{tabular}

Data refer to the samples, in terms of cellulose, hemicellulose, AIL, ASL, ash, and acetyl contents (w/w, dry weight basis). Data are means of three replicates

a acid insoluble lignin

b acid soluble lignin

c relative content (mass recovery $\times$ relative content)

(1.0 or $0.5 \mathrm{~h}$ ), was firstly increased, and then decreased as the temperature increased with peak values of $56.56 \%$ at $110{ }^{\circ} \mathrm{C}$, acid catalyzed for $1.0 \mathrm{~h}$ and $54.24 \%$ at $130{ }^{\circ} \mathrm{C}$, acid catalyzed for $0.5 \mathrm{~h}$ (Table 2). It is noted that the low relative contents of cellulose are found in R90-1.0, R120-1.0, R120-1.5, R140-0.5, and R150-0.5 samples.

Lignin in biomass was partially removed by IL with evidence of decreased lignin amount in the regenerated residues (11.26-18.49 \%, including AIL and ASL fractions). The dissolution of hemicellulose into IL-acid system contributed to a more efficient removal of lignin. A similar tendency of lignin removal to hemicellulose solubilization could be detected as lignin was covalently linked to hemicellulose to some extent. However, the relative content of lignin in pretreated samples was only slightly decreased in R90-1.0 and R100-1.0 samples but obviously increased (23.90-48.02\%) in the others. Relative contents of lignin in R90-1.0 and R100-1.0 samples were similar to those reported previously using a two-steps IL $\left(160{ }^{\circ} \mathrm{C}\right)$-Amberlyst $\left(90^{\circ} \mathrm{C}\right)$ pretreatment [23]. The highest relative content of lignin was observed in R150-0.5 sample, accompanying the lowest cellulose content. We attribute this high lignin content to the comprehensive functions of cellulose hydrolysis, hemicellulose solubilization, lignin redistribution, and the possible formation of insoluble substrates from carbohydrate conversion during acid pretreatment at high temperature $[16,30$, 31]. Further examinations are needed to find out the dominating determinant.

\section{Enzymatic digestibility of pretreated Arundo donax}

Figure 1 presents the temporal profiles of cellulose conversion from raw and pretreated $A$. donax samples under various pretreatment conditions. Since IL in substrate showed toxic or inhibitory effects on microorganisms' growth, all the samples were washed thoroughly before enzymatic hydrolysis [32]. Enzymatic saccharification assays were conducted under the same conditions to ensure the validity of comparison. As can be seen, $A$. donax substrates originating from IL-Amberlyst pretreatments were readily degraded by enzymes when compared to raw materials-enzymatic digestibilities were significantly enhanced and high cellulose conversion and high hydrolysis rate were observed.

Our results showed evidences that enzymatic saccharification enhancement depends on the Amberlyst reaction time considering the same temperature at $120{ }^{\circ} \mathrm{C}$ (Fig. 1a). The digestibilities of samples exposed to water pretreatments of the same temperature profiles were also evaluated as the heat alone might increase the cellulose digestibility. As can be seen from Additional file 1, $A$. donax subjected to IL-Amberlyst pretreatment displayed an increase of 5.32, 5.58, 6.25 folds in cellulose digestibility compared to the corresponding water pretreated samples after $0.5,1.0$, and $1.5 \mathrm{~h}$ of Amberlyst pretreatment, respectively. The highest cellulose conversion was obtained for $A$. donax pretreated at $120{ }^{\circ} \mathrm{C}$ and acid catalyzed for $1.5 \mathrm{~h}$. After $72 \mathrm{~h}$ of enzymatic hydrolysis, the glucose yield was reached up to $90.2 \%$ relative to initial level in the corresponding pretreated biomass (Fig. 1b). This was consistent with previous observations employed $\left[\mathrm{C}_{4} \mathrm{mim}\right] \mathrm{Cl}$ at a long pretreatment time or dilute acid at high temperature [12, 29]. For example, studies conducted by Trinh and coworkers [12] obtained 90\% cellulose digestion when the wood materials were pretreated with $\left[\mathrm{C}_{4} \mathrm{mim}\right] \mathrm{Cl}$ at $120{ }^{\circ} \mathrm{C}$ for $24 \mathrm{~h}$. Nevertheless, 


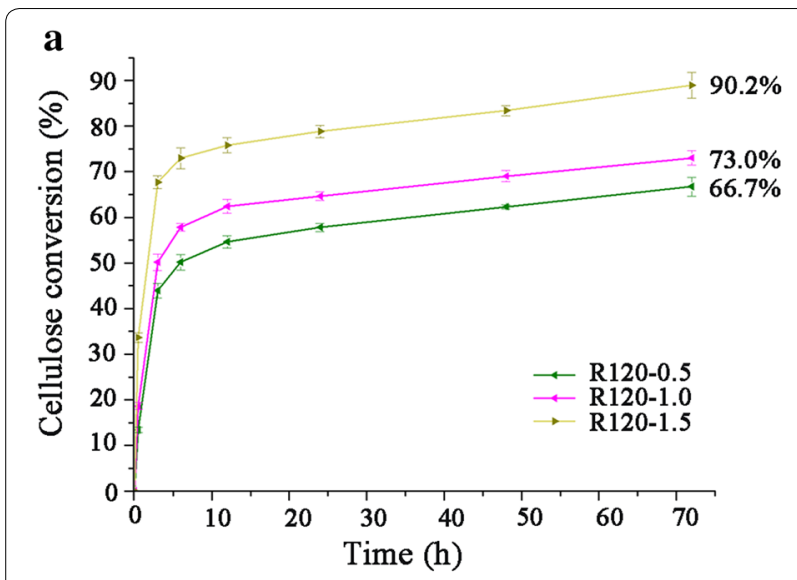

b

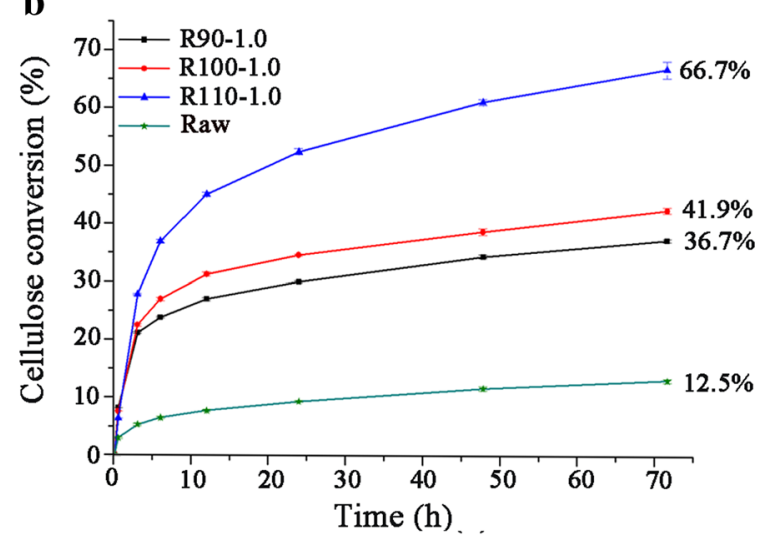

C

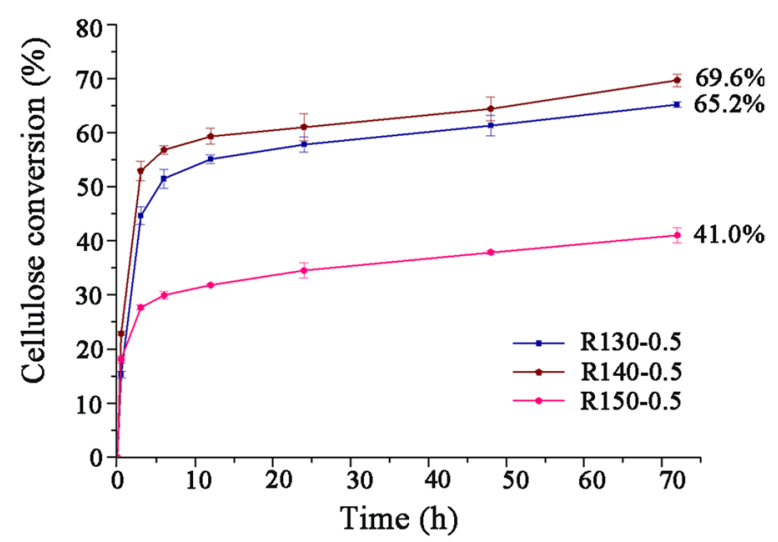

Fig. 1 Cellulose conversions of raw and pretreated A. donax. by enzymatic saccharification. Cellulose conversions expressed as percentage of the theoretical glucose in pretreated samples. $\mathbf{a}$ Effect of solid acid reaction time $(0.5,1.0$, and $1.5 \mathrm{~h})$ on enzymatic hydrolysis, $\mathbf{b}$ Effect of low pretreatment temperature $\left(90,100\right.$, and $\left.110^{\circ} \mathrm{C}\right)$ on enzymatic hydrolysis, and c effect of high pretreatment temperature (130, 140, and $150^{\circ} \mathrm{C}$ ) on enzymatic hydrolysis. Error bars indicate standard deviation of triplicate determinations. Sample code with definition is in Table 1

Uppugundla and coworkers [29] achieved nearly $100 \%$ glucan conversion for corn stover pretreated with 1-ethyl-3-methylimidazolium acetate $\left(\left[\mathrm{C}_{2} \mathrm{mim}\right][\mathrm{OAc}]\right)$ for $3 \mathrm{~h}$ at $140{ }^{\circ} \mathrm{C}$. As the cost of IL and pretreatment temperature are very important parameters for an economic analysis of IL pretreatment, the comparatively low price of $\left[\mathrm{C}_{4} \mathrm{mim}\right] \mathrm{Cl}$ (approximately $1 / 60$ th of $\left[\mathrm{C}_{2} \mathrm{mim}\right][\mathrm{OAc}]$ ) and depressed temperature used in the present study may compensate the glucose release $[18,33]$.

Samples pretreated at higher temperature with shorter acid reaction time or lower temperature with longer acid reaction time showed similar enhanced cellulose digestibilities [34]. It is interesting to note that the cellulose digestibility increases dramatically with temperature increases from 90 to $110{ }^{\circ} \mathrm{C}$, whereas decreased increments are detected when the temperature increases from 130 to $150{ }^{\circ} \mathrm{C}$ (Fig. 1b, c). According to literature, the presence of lignin in biomass hinders the enzymatic hydrolysis by nonproductive binding of cellulase to its surface [35]. High relative content of lignin in R150-0.5 sample (Table 2) could be the major factor that restricted the augment of cellulose conversion.

All of these pretreated $A$. donax showed a rapid response to enzyme addition, as seen in Fig. 1. As expected, the glucose released during enzymatic hydrolysis rose rapidly within the first $24 \mathrm{~h}$, with a slowly released afterwards. Nevertheless, as can be seen from Table 3 that the initial rates (defined as sugar released within the first $3 \mathrm{~h}$ ) of glucose released for samples pretreated at lower temperatures were between 60 and $92 \mathrm{~g} /$ $\mathrm{kg} / \mathrm{h}$ compared to $92-226 \mathrm{~g} / \mathrm{kg} / \mathrm{h}$ for samples pretreated at higher temperatures. These initial rates were apparently higher than that of switchgrass subjected to ammonia fibre expansion pretreatment conducted by Bals and coworkers [36]. In addition, a number of detectable xylose was released during the saccharification for these samples (Additional file 2). Aside from the comparatively high yields of glucose and xylose, the high mass recovery at lower pretreatment temperatures resulted in higher monomeric sugars released in pretreated samples (Table 1, Fig. 2). Both R110-1.0 and R120-0.5 samples have significantly increased total sugars recovery (29.5 and $30.9 \mathrm{~g}$ total sugar per $100 \mathrm{~g}$ starting biomass) in the enzymatic hydrolysates as compared to the 8.3 and $8.4 \mathrm{~g}$ total sugars per $100 \mathrm{~g}$ starting biomass from the corresponding water pretreated samples (Table 3, Additional file 1), which was higher than those of Arabidopsis pretreated with $\left[\mathrm{C}_{2} \mathrm{mim}\right][\mathrm{OAc}]$ at $140{ }^{\circ} \mathrm{C}$ for $3 \mathrm{~h}$ [37].

\section{Structural analysis in the pretreated Arundo donax}

As is well known, the cellulose digestibility is closely connected to the physicochemical characteristics of biomass. Morphological, chemical, and structural changes of biomass were occurred during the pretreatments to facilitate the biomass more susceptible to cellulase. Detailed 


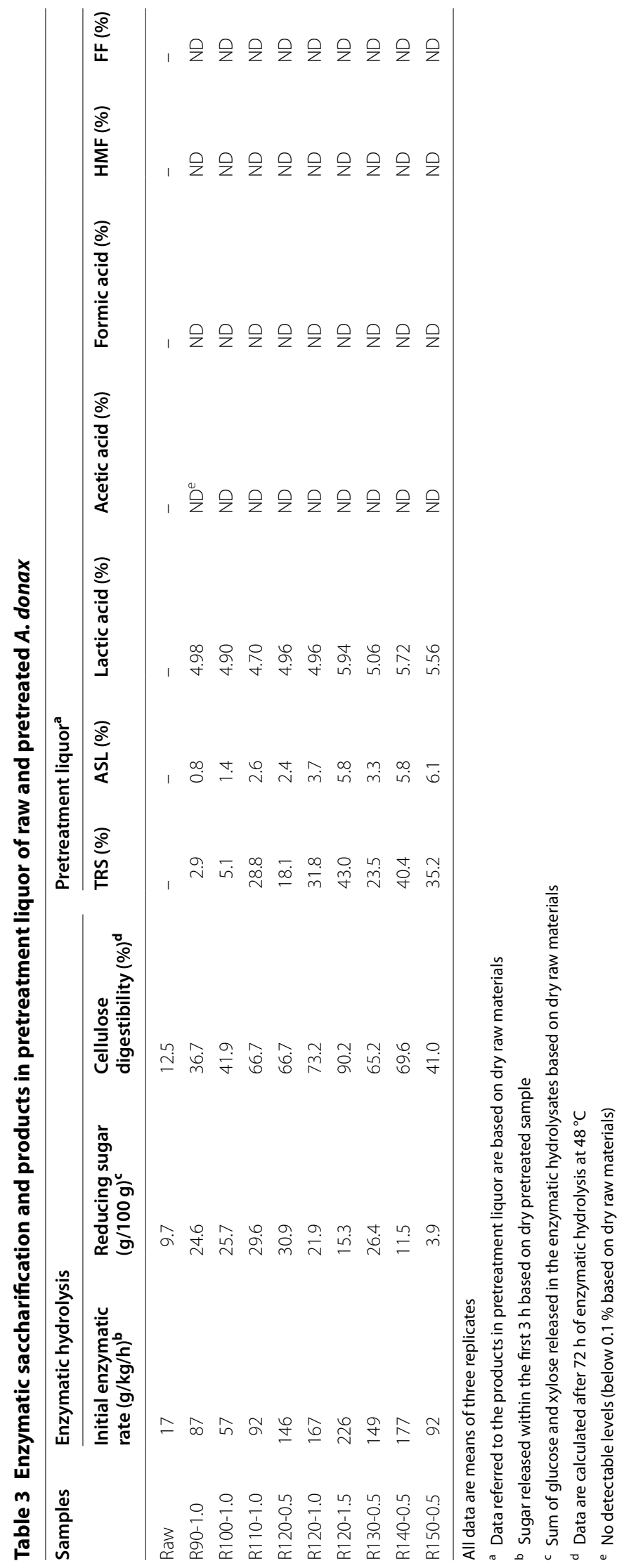




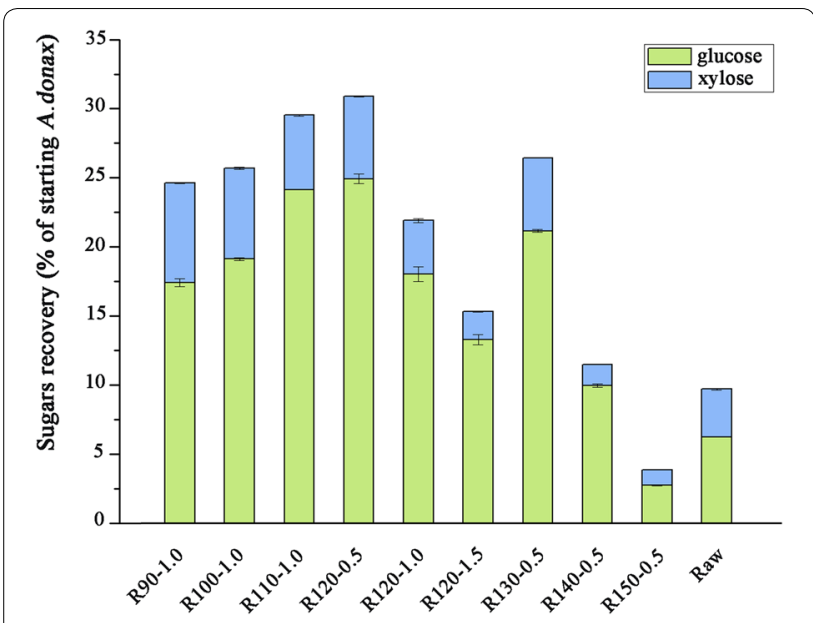

Fig. 2 Comparison of total glucose and xylose recovery of raw and pretreated $A$. donax. after enzymatic saccharification. The sugars were recovered after $72 \mathrm{~h}$ of enzymatic hydrolysis at $48^{\circ} \mathrm{C}$ and $150 \mathrm{rpm}$ and expressed as percentage of the original biomass. Error bars indicate standard deviation of triplicate determinations. Sample code with definition is in Table 1

analysis was conducted to compare the inherent features of the raw and differently pretreated substrates.

Modification of the gross morphology of the A. donax samples was analyzed by scanning electron microscopy (SEM) (Additional file 3). Results show that the raw $A$. donax had a densified smooth surface and intact fibers arranged in bundles, which prevented the accessibility of cellulase to substrates. The isothermal IL-Amberlyst pretreatment variables resulted in considerable damage in structure, exposing more cellulosic materials and contributed to high cellulose digestibility. The images of samples pretreated at low temperatures showed reversible swelling of cellulose with evidence of the twisting of separated fibres and rough surface with some cracks and fragmentations appearing when the pretreatment temperatures increased to $110{ }^{\circ} \mathrm{C}$ (Additional files 3, 4). A possible reason was the incipient disruption of hemicellulose and the onset of the delignification during the pretreatment. Re-deposition of polymers on the surface of fibre was observed in samples pretreated at high temperatures similar to those seen on wheat straw pretreated by thermal autoclaving and alkaline peroxide pretreatments [38]. When prolonging the acid reaction time, rougher and porous surfaces were visualized due to re-deposition of polymers, hemicellulose solubilisation, and lignin delignification. The increasing roughness and porosity improved the accessibility of the enzyme to fibres as reported in the previous literature [35]. Under harsher conditions $\left(150{ }^{\circ} \mathrm{C}, 0.5 \mathrm{~h}\right)$, the SEM image shows disaggregation of cell bundles and the formation of sheet-like structure with large amount of re-deposited polymers on the surface of fibres (Additional file 3). These polymers were insoluble in acid solution and added to acid insoluble lignin in R150-0.5 sample. The resulted high insoluble polymers in R150-0.5 sample evidently impeded the effective enzymatic hydrolysis (Fig. 1).

Fourier transform infrared spectroscopy (FTIR) was applied to probe the chemical differences among the raw and pretreated A. donax (Additional file 5). When compared with the raw materials, the absorption bands at 1735 and $1240 \mathrm{~cm}^{-1}$ which are assigned to $\mathrm{C}=\mathrm{O}$ stretching vibration in acetyl groups and $\mathrm{C}-\mathrm{O}$ stretching of hemicelluloses [39], respectively, were broaden in the isothermal pretreated samples. The decline of the intensities of these two bands indicated the partial removal of hemicellulose. It is clearly discernible that the intensities of bands at $1600,1510,1460$, and $834 \mathrm{~cm}^{-1}$ that associated with lignin [40] increase especially in samples of R1201.5, R140-0.5, and R150-0.5 samples, which are consistent with the increased relative contents of lignin (Table 2). Moreover, characteristic assignments of cellulose at 1635, $1424,1155,1038$, and $896 \mathrm{~cm}^{-1}$ were observed.

The changes in the crystallinity of cellulose in the untreated and pretreated materials could be established by FT-IR analysis $[41,42]$. The band at $1424 \mathrm{~cm}^{-1}$ is considered as typical of cellulose I, whereas the absorbance at $896 \mathrm{~cm}^{-1}$ represents cellulose II and the amorphous regions [43]. The absorbance ratio (lateral order index, LOI) of these two bands reflects the cellulose I fraction in cellulose structures. The increased intensity in band at $896 \mathrm{~cm}^{-1}$ in the pretreated samples (except that of R1500.5 sample) with decreased LOI values ranging from 0.56 to 1.15 (Table 1 ) indicated that the cellulose I was transformed to cellulose II to some extent. Interestingly, R150-0.5 sample had LOI value as high as 13.78. It suggested that cellulose I structure may be found in cellulose of R150-0.5 sample and the amorphous regions could almost be broken under the given condition.

$\mathrm{X}$-ray diffraction (XRD) analyses were employed to further monitor the cellulose crystalline structural changes upon the pretreatment conditions varied as a whole. The crystallinity index $(\mathrm{CrI})$ values were calculated (Table 1 ), and their XRD patterns are shown in Fig. 3. As presented, the CrI value of raw $A$. donax was $36.0 \%$, containing large proportions of crystalline cellulose. For pretreated samples, the CrI values were decreased to $16.5-31.4 \%$. After pretreatments at low temperatures, the decreased $\mathrm{CrI}$ values with increasing pretreatment temperatures were caused by the progressively increased swelling of cellulose in samples by IL [44]. The CrI values of samples pretreated at $120{ }^{\circ} \mathrm{C}$ successively slightly increased with increasing acid reaction time, which could be originated from the progressive degradation of amorphous hemicellulose and hydrolysis of amorphous cellulose. Further 


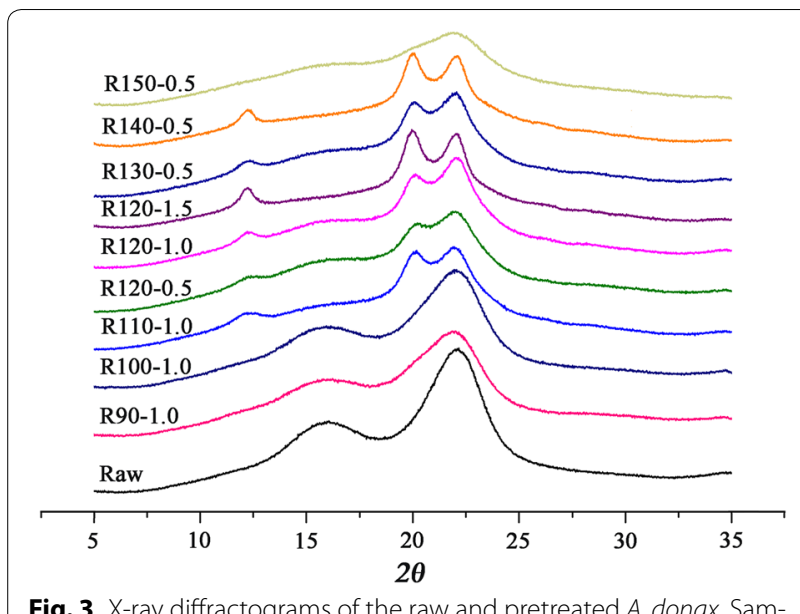

Fig. 3 X-ray diffractograms of the raw and pretreated A. donax. Sample code with definition is in Table 1

increase in the pretreatment temperature to $150{ }^{\circ} \mathrm{C}$, highly amorphous with a minor crystalline component $(\mathrm{CrI}=16.5 \%)$ were noted which primary ascribed to further depolymerization of crystalline cellulose. According to Morais and coworkers, a perfect linear relationship between the CrI values and cellulose contents was found for wheat straw pretreated by imidazole [42]. However, no obvious relationship existed between cellulose content and crystallinity (both CrI and LOI values) in the present study, which may owe to the synergistic effects of ionic liquid and solid acid on A. donax.

The regeneration processes of IL based pretreatments can change the cellulose crystal structures by disrupting inter- and intra-chain hydrogen bonding of the cellulose fibrils in the native state. The diffraction patterns of the raw biomass exhibited typical diffractions of cellulose I and only the decreasing in magnitudes were detected in samples pretreated at $90-100{ }^{\circ} \mathrm{C}$. When the samples pretreated at temperatures higher than $100{ }^{\circ} \mathrm{C}$ (excepted that of R150-0.5 sample), the peak at $22.6^{\circ}$ shifted to lower angles and the composite peak at around $15.5^{\circ}$ became vanishingly small. Moreover, a small shoulder peak at around $12.5^{\circ}$ (reflection 110 , cellulose II) was also observed (Fig. 3), indicating cellulose I lattice was severely distorted and partially transferred to cellulose II in these samples [44]. These results supported the observation made by FTIR analysis. It is noteworthy that samples pretreated at $120^{\circ} \mathrm{C}, 1.5 \mathrm{~h}$ and $140{ }^{\circ} \mathrm{C}, 0.5 \mathrm{~h}$ displayed striking diffractions of cellulose II at $12.5^{\circ}, 20.5^{\circ}$, and $22.1^{\circ}$ (Fig. 3). According to Chundawat and coworkers [45] and Wada and coworkers [46], the cellulose crystal structure transformation from cellulose I to cellulose II or III $_{\mathrm{I}}$ increases its enzymatic hydrolysis by decreasing the number of cellulose intra-sheet hydrogen bonds. The conversion of cellulose I to expended cellulose I and II definitely increased the cellulose digestibility (Fig. 1).

\section{Evaluation of total reducing sugars and inhibitors in pretreatment liquor}

Total reducing sugars (TRS) released during the pretreatments were determined in the IL liquors and the results are present in Fig. 4. The percentage of TRS in the IL-water phase was found to rely on the pretreatment conditions. At temperatures less than or equal to $100{ }^{\circ} \mathrm{C}$ and acid catalyzed for $1 \mathrm{~h}$, only about $5 \%$ of TRS was observed based on the starting $A$. donax, primary resulting from hemicellulose degradation. Comparatively, approximately $30 \%$ of TRS was obtained when at an elevated temperature $\left(110^{\circ} \mathrm{C}\right)$. It is confirmed that the high temperature shortened the incubation period of solid acid reaction [25]. It is worth noted that there may be a strong positive correlation $\left(R^{2}=0.99\right)$ between the acid reaction time and TRS released when the pretreatment temperature is $120{ }^{\circ} \mathrm{C}$ (Additional file 6). The highest TRS yield of $43.0 \%$ based on starting materials was found in the IL liquor of acid catalyzed for $1.5 \mathrm{~h}$. This value was comparable to that obtained in the hydrolysate by pretreated the switchgrass with $\left[\mathrm{C}_{4} \mathrm{mim}\right] \mathrm{Cl}$ at $160{ }^{\circ} \mathrm{C}$ for $1.5 \mathrm{~h}$, followed by acidolysis by $4 \mathrm{M} \mathrm{HCl}$ at $105^{\circ} \mathrm{C}$ for $2.5 \mathrm{~h} \mathrm{[17]} \mathrm{and} \mathrm{pretreated} \mathrm{the} \mathrm{bermuda} \mathrm{grass} \mathrm{with} \mathrm{dilute}$ acid at $121{ }^{\circ} \mathrm{C}$ for $1 \mathrm{~h} \mathrm{[47]}$. Despite similar sugars yields could be achieved by other IL based and traditional dilute acid pretreatments, this process provides a convenient, mild, and recyclable alternative method for in situ sugars production. However, a slight decrease of TRS yield in R150-0.5 sample was probably due to the decomposition of TRS to form insoluble substrates at high temperature, such as humins.

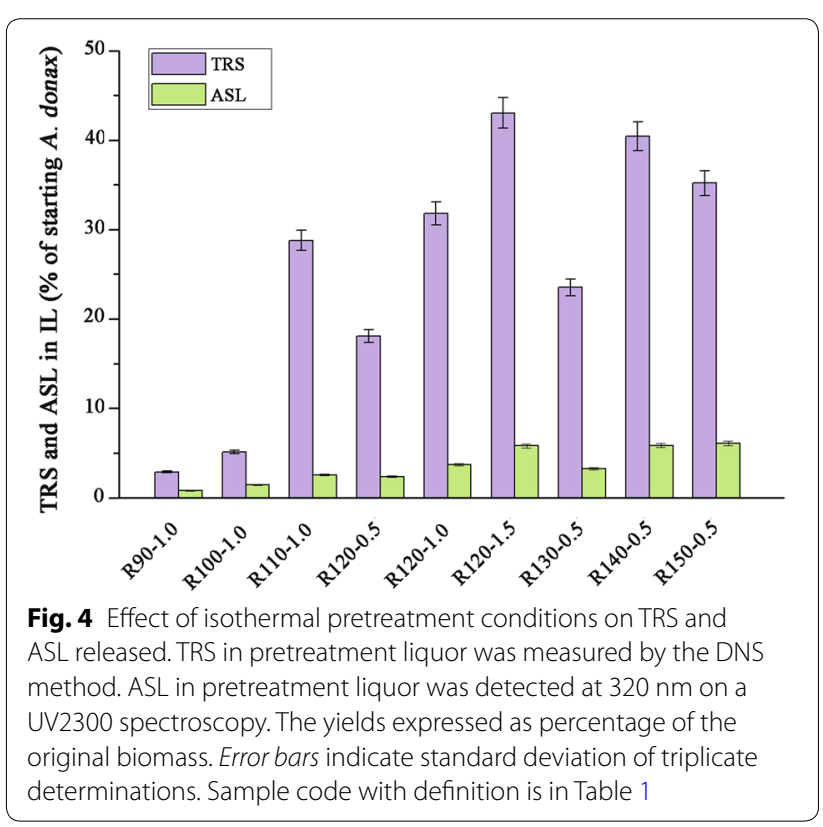


It is known that cellulose dissolved in $\left[\mathrm{C}_{4} \mathrm{mim}\right] \mathrm{Cl}$ releases reducing sugars in the presence of solid acid catalysts. Our results corroborate those of other studies, such as Rinaldi and coworkers [16], Zhang and coworkers [48], Yamaguchi and coworkers [49], and Guo and coworkers [50]. They also reported that cellulose can be hydrolysed by solid acid catalysts, such as a carbon material bearing $\mathrm{SO}_{3} \mathrm{H}\left(100{ }^{\circ} \mathrm{C}, 3 \mathrm{~h}\right)$, zeolites $\left(100{ }^{\circ} \mathrm{C}, 6 \mathrm{~h}\right)$ and magnetic solid acid $\left(150^{\circ} \mathrm{C}, 2 \mathrm{~h}\right)$. A comparatively high TRS released was detected in the IL liquors of R120-1.0, R120-1.5, R140-0.5, and R150-0.5 samples (31.8-43.0 \%). Taking into account the low cellulose content (Table 2), it was demonstrated that cellulose depolymerization was the determining factor of TRS released at temperatures higher than $120^{\circ} \mathrm{C}$. It is not surprising that the relative contents of lignin increase in samples pretreated at high temperature due to the cellulose hydrolysis (Table 2). Sun and coworkers [17] have reported that sugars in IL can be extracted by a biphasic system. The recovery of sugars in $\left[\mathrm{C}_{4} \mathrm{mim}\right] \mathrm{Cl}$ provides higher combined monomeric sugars released from the starting $A$. donax (Table 3 ).

Acid pretreatment is recognized to produce by-products considered inhibitory to microbial fermentation from carbohydrates [51, 52]. However, a quite different by-product distribution was obtained by Brønsted acid pretreatment in the present study. As can be seen from Table 3, no detectable levels (below $0.1 \%$ based on dry raw materials) of routine inhibitors were found in any of the hydrolysates; whereas $4.7-5.94 \%$ of lactic acid was obtained based on the dry raw materials. The lactic acid concentration obtained here was higher than that produced after 3 months of incubation by lactic acid bacteria during the solid state fermentation of forage rice round bales [53]. It was reported that cellulose can be converted to lactic acid in the presence of solid Lewis acids in water or solid Brønsted acid [20, 22]. Despite relatively high amount of lactic acid was produced during the pretreatment; this output had little effect on the further processes [52]. Lignin can also act as an inhibitor for fermentation. In terms of acid soluble lignin (ASL), 0.78-6.10\% of starting material was detected in pretreatment liquors and a similar tendency of lignin solubilizing to TRS released was seen (Table 3; Fig. 4). Regeneration of these soluble lignins from liquors is believed to reduce the inhibitory. The recovery of lactic acid and acid soluble lignin during IL-Amberlyst pretreatment may offset the high cost of IL.

\section{Process mass balance}

In this study, the maximum TRS yield and enzymatic saccharification were achieved at $120{ }^{\circ} \mathrm{C}$ and acid catalyzed for $1.5 \mathrm{~h}$, whereas the comparatively high total glucose and xylose yields in enzymatic hydrolysates were obtained at $120^{\circ} \mathrm{C}$ and acid catalyzed for $0.5 \mathrm{~h}$ and $110^{\circ} \mathrm{C}$ and acid catalyzed for $1.0 \mathrm{~h}$. Therefore, process mass balances of the isothermal pretreatments were developed for these three conditions (Fig. 5). All data were based on experimental results starting from $100 \mathrm{~g}$ of raw $A$. donax. The pretreatments used $1900 \mathrm{~g}$ of IL and $20 \mathrm{~g}$ of Amberlyst 35DRY per $100 \mathrm{~g}$ of the materials. About $96 \%$ of IL can be recycled by an aqueous biphasic system, following distillation of residual water for further reuse [54], and the solid acid resins were recovered by sieving the solid fractions.

Taking into account the cellulose conversion and mass recovery, maximum glucose and xylose produced in enzymatic hydrolysates were 24.9 and $6.0 \mathrm{~g}$ when biomass pretreated at $120^{\circ} \mathrm{C}$ and acid catalyzed for $0.5 \mathrm{~h}$. A similar glucose $(24.2 \mathrm{~g})$ and xylose $(5.4 \mathrm{~g})$ production was found at $110{ }^{\circ} \mathrm{C}$ and acid catalyzed for $1.0 \mathrm{~h}$. As the TRS released increased with increasing acid reaction time, a higher combined sugars yield was obtained for the latter one. In the case of pretreatment at $110{ }^{\circ} \mathrm{C}$ and acid catalyzed for $1.0 \mathrm{~h}, 85.0 \%$ of total reducing glycan (glucan, xylan, arabinan, and galactan) in raw materials was obtained, higher than $76 \%$ of recovery from corn stover subjected to dilute acid pretreatment carried by Uppugundla and coworkers [29]. $4.7 \mathrm{~g}$ of lactic acid and $2.6 \mathrm{~g}$ of acid soluble lignin were produced during this pretreatment. Despite highest cellulose conversion for R120-1.5 (Fig. 1), only $32 \mathrm{~g}$ biomass was recovered, resulting in the low total glucose and xylose yields in enzymatic hydrolysates. However, prolonged acid reaction time enhanced the sugar released during the pretreatment. It was found that $43.0 \mathrm{~g}$ of TRS could be obtained in this way. Considering the enzymatic hydrolysis, it was possible to convert $84.9 \%$ of initial total reducing glycan. Reduction of the costly hydrolytic enzymes for sugar released suggests that this process may offer compelling economic advantages. Addition to the sugars recovery, $5.9 \mathrm{~g}$ of lactic acid and $5.8 \mathrm{~g}$ of soluble lignin byproducts were also obtained which will further reduce the cost of pretreatment. Therefore, this process provides an alternative way to produce fermentable sugars cost-effectively.

\section{Conclusions}

In this work, energy favorable facile isothermal $\left[\mathrm{C}_{4} \mathrm{mim}\right] \mathrm{Cl}$ Amberlyst 35DRY pretreatment was proposed to enhance the combined sugars yields in enzymatic hydrolysates and pretreatment liquors. During the pretreatments, it was found that hemicellulose removal, cellulose hydrolysis, crystalline conversion, and polymer re-deposition were dependent on pretreatment conditions since the liberation of $\mathrm{H}_{3} \mathrm{O}^{+}$into IL were temperature- and time-dependent. Under the optimal condition IL pretreated at $110{ }^{\circ} \mathrm{C}$ for 


\section{a}
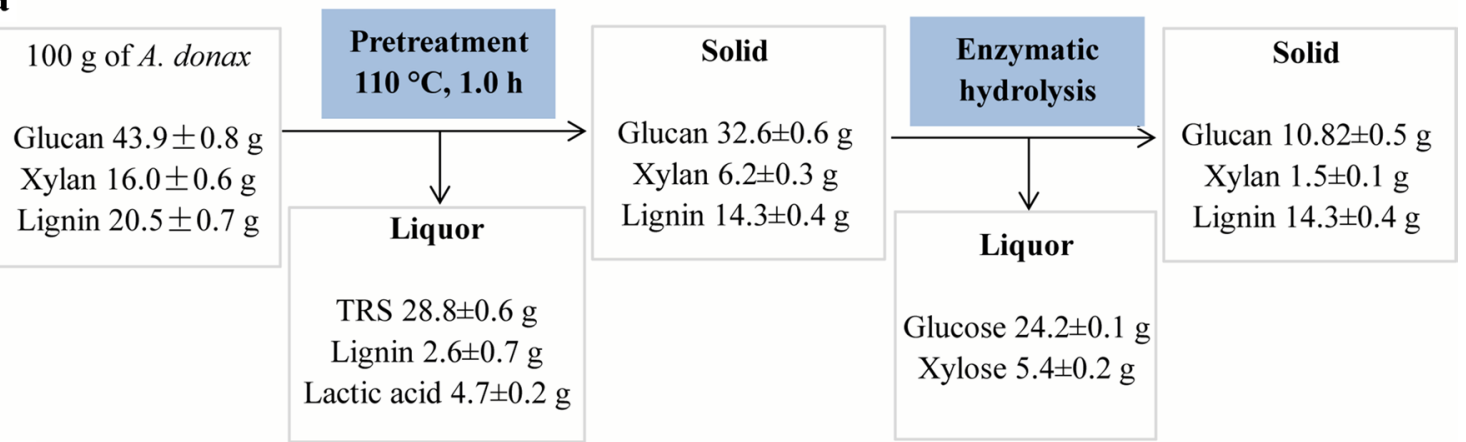

Glucose $24.2 \pm 0.1 \mathrm{~g}$

Xylose $5.4 \pm 0.2 \mathrm{~g}$

b
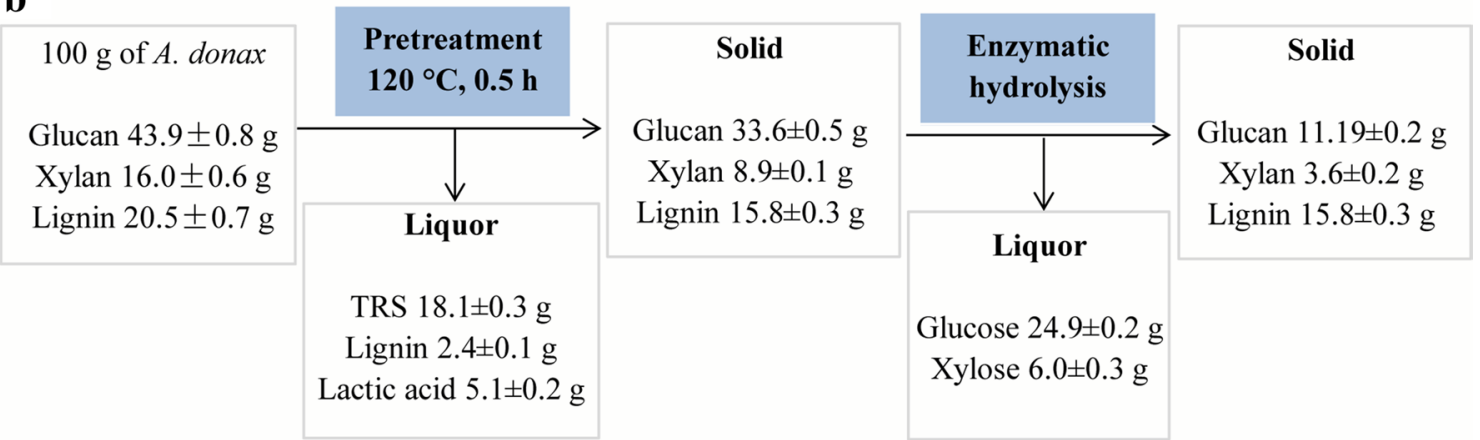

Glucose $24.9 \pm 0.2 \mathrm{~g}$

Xylose $6.0 \pm 0.3 \mathrm{~g}$

c
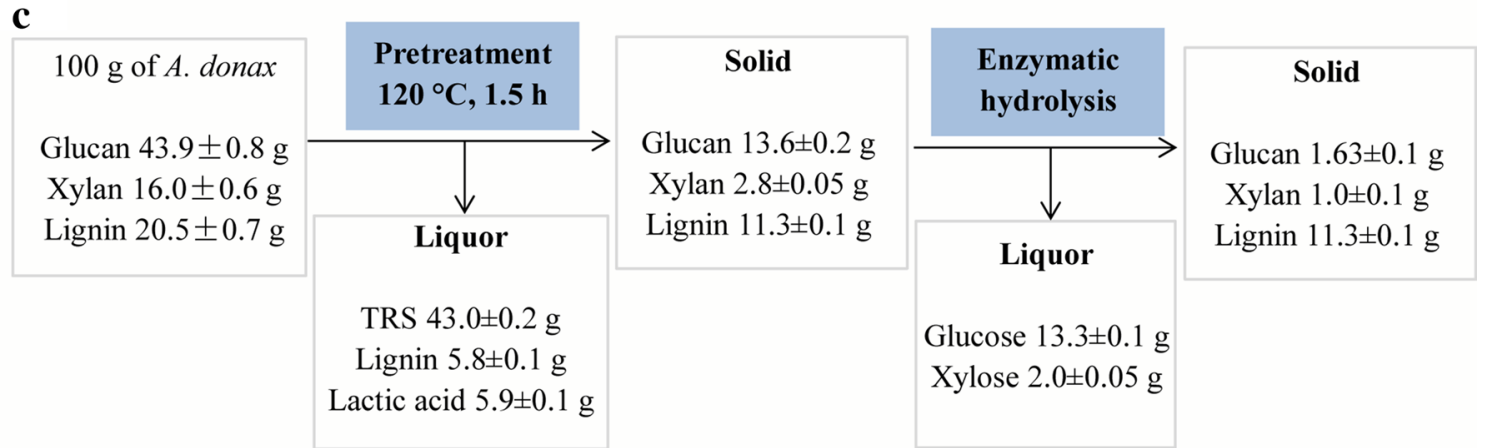

Fig. 5 Mass balance of $\left[\mathrm{C}_{4} \mathrm{mim}\right] \mathrm{Cl}$-Amberlyst 35DRY isothermal pretreatment for the selected conditions. a IL pretreated at $110^{\circ} \mathrm{C}$, following by solid acid Amberlyst 35DRY catalyzed for $1.0 \mathrm{~h}$, b $\mathrm{L}$ pretreated at $120^{\circ} \mathrm{C}$, following by solid acid Amberlyst 35DRY catalyzed for $0.5 \mathrm{~h}$, and $\mathbf{c} \mathrm{LL}$ pretreated at $120^{\circ} \mathrm{C}$, following by solid acid Amberlyst 35DRY catalyzed for $1.5 \mathrm{~h}$. Mass balanced adjusted to $100 \mathrm{~g}$ starting biomass. Values presented $\pm S D$

$3.0 \mathrm{~h}$ and subsequent acid reaction for $1.0 \mathrm{~h}, 24.2 \mathrm{~g}$ glucose and $5.4 \mathrm{~g}$ xylose in enzymatic hydrolysate and $28.8 \mathrm{~g}$ TRS in pretreatment liquor were produced without any notable deleterious effects. This process could potentially recover $85.0 \%$ of the total reducing glycan in the untreated $A$. donax under a moderate temperature. Moreover, the production of lactic acid and lignin by-products will especially increase the economic prospects. Clearly, the facile isothermal $\left[\mathrm{C}_{4} \mathrm{mim}\right] \mathrm{Cl}$-Amberlyst 35DRY pretreatment provides an emerging strategy for fermentable sugars production and new revenues energy-efficiently which make
IL technology a serious candidate for an industrially based biorefinery process.

\section{Methods \\ Arundo donax preparation}

One-year-old $A$. donax was spring harvested and kindly provided by the Beijing Academy of Agriculture and Forestry Sciences, China. The foliage was removed, and the dried stems were knife-milled and passed through $0.3 \mathrm{~mm}$ screen. These lignocellulosic materials were then exhaustively extracted with toluene/ethanol $(2: 1, \mathrm{v} / \mathrm{v})$ in 
a Soxhlet apparatus, oven-dried at $40{ }^{\circ} \mathrm{C}$ for $16 \mathrm{~h}$, and stored in a sealed bag at room temperature for further use. The dry matter content in biomass was $97 \%(w / w)$.

\section{Ionic liquid-Amberlyst pretreatment}

1-butyl-3-methylimidazolium chloride, $\left[\mathrm{C}_{4} \mathrm{mim}\right]^{+} \mathrm{Cl}^{-}$ with stated purity $\geq 98.5 \%$, was purchased from Lanzhou Institute of Chemical Physics of the Chinese Academy of Sciences (Lanzhou, China) and used as the IL for all pretreatments. The water content in IL was 960 ppm as determined by a volumetric Karl-Fischer titration. Solid acid Amberlyst 35DRY was acquired from the Dow Chemical Company (Michigan, America) and sieved to 20 mesh $(0.425-0.850 \mathrm{~mm})$. The isothermal pretreatments were performed in a $250 \mathrm{~mL}$ dried three-neck flask. Firstly, $5.0 \mathrm{~g}$ of $A$. donax was pretreated with $95.0 \mathrm{~g}$ of $\left[\mathrm{C}_{4} \mathrm{mim}\right] \mathrm{Cl}$ at $90,100,110,120,130,140$, and $150{ }^{\circ} \mathrm{C}$ with stirring at $100 \mathrm{rpm}$ for $3 \mathrm{~h}$, respectively. Then $1 \mathrm{~g}$ of Amberylst catalyst was isothermally added to the corresponding slurry and kept at 90,100 , or $110^{\circ} \mathrm{C}$ for $1.0 \mathrm{~h}, 120^{\circ} \mathrm{C}$ for different periods $(0.5,1.0$, or $1.5 \mathrm{~h})$, or 130,140 , or $150{ }^{\circ} \mathrm{C}$ for $0.5 \mathrm{~h}$ with stirring at $100 \mathrm{rpm}$. After reaction time was completed, $300 \mathrm{~mL}$ of deionized water was added whilst stirring vigorously to precipitate the biomass. The mixture of IL, water, biomass, and solid resin was centrifuged to separate the liquid (IL and water) and solid (regenerated biomass and resin) phases. The recovered solids were washed thoroughly with hot water for 4-6 times to remove residual IL and freezedried. The pretreated A. donax samples were then gained by passing through a $0.425 \mathrm{~mm}$ sieve and used for analysis. Water pretreatments following the same temperature and time profiles were conducted to compare the cellulose digestibility.

\section{Compositional analysis}

The chemical composition and acetyl content of raw and pretreated $A$. donax samples were determined according to analytical procedures established by NREL [ 55 , 56]. More details were described in the literature [26]. All assays were performed in triplicate.

\section{Enzymatic saccharification}

The enzymatic saccharification of raw and pretreated $A$. donax samples was performed in a $0.05 \mathrm{M}$ sodium acetate buffer with a pH of 4.8 at a biomass loading of $2 \%$ $(\mathrm{w} / \mathrm{v})$ in an air-shaking incubator at $48{ }^{\circ} \mathrm{C}$ and $150 \mathrm{rpm}$ for $72 \mathrm{~h}$. For hydrolysis reaction, $25 \mathrm{mg}$ protein/g substrate of cellulase cocktail (Novozyme) was used to reach an enzyme loading of 20 filter paper units (FPU)/g substrate. To monitor hydrolysis kinetics, $100 \mu \mathrm{L}$ of hydrolyzed slurry was taken periodically $(0,0.5,3,6,12,24$,
48, and $72 \mathrm{~h}$ ). The hydrolysis reaction was terminated by boiling the hydrolyzed slurry for $5 \mathrm{~min}$. After cooling, the hydrolyzed slurry was centrifuged at $10,000 \mathrm{~g}$ for $5 \mathrm{~min}$ and then the supernatant was collected and filtered through a $0.45 \mu \mathrm{m}$ syringe filter for HPAEC analysis. Results are presented as percentage of the corresponding theoretical glucose yield of each sample. All assays were performed in triplicate.

\section{Fourier transform infrared spectroscopy}

FTIR spectra of samples were obtained with a Thermo Scientific Nicolet iN 10 FTIR Microscopy (Madison, America) equipped with a liquid nitrogen cooled MCT detector. Spectra were collected from 1800 to $800 \mathrm{~cm}^{-1}$ at room temperature. 32 scans were taken for each sample and the distinguishability was $4 \mathrm{~cm}^{-1}$. The FTIR absorption spectra of raw and pretreated $A$. donax were baseline correction and normalized to the highest peak [40].

\section{X-ray diffraction}

Crystallinity of raw and pretreated A. donax samples was analyzed by powder X-ray diffraction in a D8 Advance instrument (Bruker AXS) employing Ni-filtered $\mathrm{Cu} \mathrm{K \alpha}$ radiation (wavelength $=0.154 \mathrm{~nm}$ ) at $40 \mathrm{kV}$ and $30 \mathrm{~mA}$. Scans were obtained from $5^{\circ}$ to $35^{\circ} 2 \theta$ (Bragg angle) at $0.03^{\circ}$ per second of scanning rate and at room temperature. Sample was packed into an aluminum sample holder and run as received for data collection. Sample crystallinity, as expressed by crystallinity index (CrI) was measured from the XRD data and calculated with the following formula proposed by Segal et al. [57]:

$$
\mathrm{CrI}=\frac{I_{002}-I_{\mathrm{am}}}{I_{002}} \times 100
$$

in which $I_{002}$ is the scattered intensity of 002 peak (cellulose I) at about $2 \theta=22.5^{\circ}$, and $I_{\text {am }}$ is the scattered intensity of peak in the amorphous phase at about $2 \theta=18.5^{\circ}$.

\section{Scanning electron microscopy}

The morphology of raw and pretreated $A$. donax samples was examined by scanning electron microscopy. The SEM images were recorded with a Hitachi S-3400 N scanning electron microscope operated at $10 \mathrm{kV}$ acceleration voltages. All the samples were spread on a metalcylinder plate with a carbon tape and coated with gold prior to examination.

\section{Analysis of pretreatment liquors}

Total reducing sugars in ionic liquid solution were colorimetrically measured at $540 \mathrm{~nm}$ on a UV spectrophotometer using the DNS method [58]. D-glucose was applied as a standard and the concentration of TRS was calculated 
based on a standard curve obtained with D-glucose $\left(\mathrm{A}=0.1404 \mathrm{c}-0.0888, \mathrm{R}^{2}=0.9994\right)$. For acid soluble lignin determination, the ionic liquid solution was diluted to bring the absorbance at $320 \mathrm{~nm}$ into the range of $0.7-$ 1.0. Inhibitors (lactic acid, acetic acid, HMF, formic acid, and furfural) in ionic liquid solution were analyzed using an Agilent 1200 high performance liquid chromatography (HPLC) instrument equipped with a Bio-Rad HPX87P ion-exclusion column. Degassed $0.01 \mathrm{~N}$ dilute $\mathrm{H}_{2} \mathrm{SO}_{4}$ solution was used as the mobile phase with a flow rate of $0.6 \mathrm{ml} / \mathrm{min}$, while the temperature in the column was kept constant at $50^{\circ} \mathrm{C}$. All assays were carried out in triplicate.

\section{Additional files}

Additional file 1. Enzymatic hydrolysis of raw and water pretreated $A$. donax. The raw samples were exposed to the same temperature profiles as that of IL-Amberlyst pretreatments. Data are means of three replicates. Ratio $=$ digestibility $_{\text {L-Amberlyst }} /$ digestibility $_{\text {hot water }}$

Additional file 2. Xylose released during enzymatic hydrolysis. Error bars indicate standard deviation of triplicate determinations. Sample code with definition is in Table 1.

Additional file 3. SEM images of the raw and $\left[\mathrm{C}_{4} \mathrm{mim}\right] \mathrm{Cl}$-Amberlyst 35DRY isothermal pretreated A. donax. at magnification $\times 2000$. Sample code with definition is in Table 1.

Additional file 4. SEM images of the raw and $\left[\mathrm{C}_{4} \mathrm{mim}\right] \mathrm{Cl}-\mathrm{Amberlyst}$ 35DRY isothermal pretreated $A$. donax. at magnification $\times 100$. Sample code with definition is in Table 1.

Additional file 5. FTIR spectra of the raw and $\left[\mathrm{C}_{4} \mathrm{mim}\right] \mathrm{Cl}$-Amberlyst 35DRY isothermal pretreated A. donax. The band at $896 \mathrm{~cm}^{-1}$ is attributed to glucose ring stretch, $\mathrm{C1}-\mathrm{H}$ deformation, which represents cellulose II and the amorphous regions. The band at $1043 \mathrm{~cm}^{-1}$ is assigned to $\mathrm{C}-\mathrm{O}$ stretching vibration in cellulose and hemicelluloses. The shift of this band to lower wavenumber supported a significant loss of crystallinity of cellulose after treatment. The band at $1424 \mathrm{~cm}^{-1}$ referred to $\mathrm{CH} 2$ scissoring at C (6) in cellulose, which is considered as typical of cellulose I. The dashed line on the left referred to band at $1424 \mathrm{~cm}^{-1}$, the middle one referred to band at around $1043 \mathrm{~cm}^{-1}$, and the right one referred to the band at $896 \mathrm{~cm}^{-1}$. Sample code with definition is in Table 1.

Additional file 6. Experimental data and the simulated line for TRS released as a function of acid reaction time. The pretreatment temperature was $120^{\circ} \mathrm{C}$. Data were means of three replicates. A positive correlation between the acid reaction time and TRS released was found: TRS yield $=24.9415 \times \mathrm{t}+6.02925\left(R^{2}=0.99\right)$.

\section{Abbreviations}

IL: ionic liquid; $\left[\mathrm{C}_{4} \mathrm{mim}\right] \mathrm{Cl}$ : 1-n-butyl-3-methylimidazolium chloride; $\left[\mathrm{C}_{2} \mathrm{mim}\right]$ [OAc]: 1-ethyl-3-methylimidazolium acetate; TRS: total reducing sugars; AlL: acid insoluble lignin; ASL: acid soluble lignin; FF: furfural; HMF: 5-hydroxymethyl furfural; SEM: scanning electron microscopy; FTIR: Fourier transform infrared spectroscopy; XRD: X-ray diffraction; Crl: crystallinity index.

\section{Authors' contributions}

TTY participated in the design of the study, carried out the pretreatments, enzymatic hydrolysis, FTIR, XRD, and SEM, analyzed the data and drafted the manuscript. LPS participated in the determination of chemical composition in pretreated samples and helped to interpret the data. RZW participated in the TRS and ASL determination in pretreatment liquor. LMZ participated in the materials preparation. FX conceived of the study, coordinated the overall study, participated in the analysis of the results and their discussion, and revised the manuscript critically before submission. All authors read and approved the final manuscript.

\section{Acknowledgements}

The authors thank the Beijing Academy of Agriculture and Forestry Sciences for providing the raw A. donax. They would also like to thank the reviewers for positive criticism to improve the quality of the manuscript.

\section{Competing interests}

The authors declare that they have no competing interests.

\section{Availability of supporting data}

All data supporting our findings can be found in the Additional files 1, 2, 3, 4, 5 , and 6 .

\section{Funding}

This study was funded by the Fundamental Research Funds for the Central Universities (No. 2015ZCQ-CL-03) and the Chinese Ministry of Education (113014A).

Received: 3 May 2016 Accepted: 15 August 2016

Published online: 24 August 2016

\section{References}

1. Claassen P, Van Lier J, Contreras AL, Van Niel E, Sijtsma L, Stams A, et al. Utilisation of biomass for the supply of energy carriers. Appl Microbiol Biotechnol. 1999;52(6):741-55.

2. Corno L, Pilu R, Adani F. Arundo donax L.: a non-food crop for bioenergy and bio-compound production. Biotechnol Adv. 2014;32(8):1535-49.

3. David K, Ragauskas AJ. Switchgrass as an energy crop for biofuel production: a review of its ligno-cellulosic chemical properties. Energ Environ Sci. 2010;3(9):1182-90.

4. Sousa LD, Chundawat SPS, Balan V, Dale BE. 'Cradle-to-grave' assessment of existing lignocellulose pretreatment technologies. Curr Opin Biotechnol. 2009;20(3):339-47.

5. Mora-Pale M, Meli L, Doherty TV, Linhardt RJ, Dordick JS. Room temperature ionic liquids as emerging solvents for the pretreatment of lignocellulosic biomass. Biotechnol Bioeng. 2011;108(6):1229-45.

6. Soudham VP, Raut DG, Anugwom I, Brandberg T, Larsson C, Mikkola JP. Coupled enzymatic hydrolysis and ethanol fermentation: ionic liquid pretreatment for enhanced yields. Biotechnol Biofuels. 2015;8(1):135-47.

7. George A, Brandt A, Tran K, Zahari SMS-NS, Klein-Marcuschamer D, Sun N, et al. Design of low-cost ionic liquids for lignocellulosic biomass pretreatment. Green Chem. 2015;17:1728-34.

8. da Costa Lopes AM, Bogel-Łukasik R. Acidic ionic liquids as sustainable approach of cellulose and lignocellulosic biomass conversion without additional catalysts. Chem Sus Chem. 2015:8:947-65.

9. Achinivu EC, Howard RM, Li G, Gracz H, Henderson WA. Lignin extraction from biomass with protic ionic liquids. Green Chem. 2014;16(3):1114-9.

10. Bose S, Armstrong DW, Petrich JW. Enzyme-catalyzed hydrolysis of cellulose in ionic liquids: a green approach toward the production of biofuels. J Phys Chem B. 2010;114(24):8221-7.

11. Li CL, Tanjore D, He W, Wong J, Gardner JL, Thompson VS, et al. Scale-up of ionic liquid-based fractionation of single and mixed feedstocks. Bioener Res. 2015;8(3):982-91.

12. Trinh LTP, Lee YJ, Lee JW, Lee HJ. Characterization of ionic liquid pretreatment and the bioconversion of pretreated mixed softwood biomass. Biomass Bioenerg. 2015;81:1-8.

13. Fu DB, Mazza G. Aqueous ionic liquid pretreatment of straw. Bioresour Technol. 2011:102(13):7008-11.

14. Weerachanchai $P$, Lee JM. Effect of organic solvent in ionic liquid on biomass pretreatment. Acs Sustain Chem Eng. 2013;1 (8):894-902.

15. Groff D, George A, Sun N, Sathitsuksanoh N, Bokinsky G, Simmons BA, et al. Acid enhanced ionic liquid pretreatment of biomass. Green Chem. 2013;15(5):1264-7.

16. Rinaldi R, Palkovits R, Schüth F. Depolymerization of cellulose using solid catalysts in ionic liquids. Angew Chem Int Ed. 2008;47(42):8047-50.

17. Sun N, Liu H, Sathitsuksanoh N, Stavila V, Sawant M, Bonito A, et al. Production and extraction of sugars from switchgrass hydrolyzed in ionic liquids. Biotechnol Biofuels. 2013;6(1):39-52. 
18. Tadesse H, Luque R. Advances on biomass pretreatment using ionic liquids: an overview. Energ Environ Sci. 2011;4(10):3913-29.

19. Harmer MA, Sun Q. Solid acid catalysis using ion-exchange resins. Appl Catal Gen. 2001;221(1):45-62.

20. Chambon F, Rataboul F, Pinel C, Cabiac A, Guillon E, Essayem N. Cellulose hydrothermal conversion promoted by heterogeneous Brønsted and Lewis acids: remarkable efficiency of solid Lewis acids to produce lactic acid. Appl Catal B-Environ. 2011;105(1-2):171-81.

21. da Costa Lopes AM, Brenner M, Falé P, Roseiro LB, Bogel-Łukasik R. Extraction and purification of phenolic compounds from lignocellulosic biomass assisted by ionic liquid, polymeric resins, and supercritical $\mathrm{CO}_{2}$. ACS Sus Chem Eng. 2016. doi:10.1021/acssuschemeng.5b01600.

22. Holm MS, Saravanamurugan S, Taarning E. Conversion of sugars to lactic acid derivatives using heterogeneous zeotype catalysts. Science. 2010;328(5978):602-5.

23. You T, Zhang L, Zhou S, Xu F. Protic acid resin enhanced 1-butyl-3-methylimidazolium chloride pretreatment of Arundo donax Linn. Bioresour Technol. 2014;167:574-7.

24. Meine N, Benedito F, Rinaldi R. Thermal stability of ionic liquids assessed by potentiometric titration. Green Chem. 2010;12(10):1711-4.

25. Rinaldi R, Meine N, Stein J, Palkovits R, Schuth F. Which controls the depolymerization of cellulose in ionic liquids: the solid acid catalyst or cellulose. Chemsuschem. 2010;3(2):266-76.

26. You T, Mao J, Yuan T, Wen J, Xu F. Structural elucidation of the lignins from stems and foliage of Arundo donax Linn. J Agric Food Chem. 2013;61(22):5361-70.

27. da Costa Lopes AM, João KG, Rubik DF, Bogel-Łukasik E, Duarte LC, Andreaus J, et al. Pre-treatment of lignocellulosic biomass using ionic liquids: wheat straw fractionation. Bioresour Technol. 2013;142:198-208.

28. Lan W, Liu CF, Sun RC. Fractionation of bagasse into cellulose, hemicelluloses, and lignin with ionic liquid treatment followed by alkaline extraction. J Agric Food Chem. 2011;59(16):8691-701.

29. Uppugundla N, Sousa LD, Chundawat SPS, Yu XR, Simmons B, Singh $S$, et al. A comparative study of ethanol production using dilute acid, ionic liquid and AFEX ${ }^{(\mathrm{TM})}$ pretreated corn stover. Biotechnol Biofuels. 2014;7:72-85

30. Sievers C, Musin I, Marzialetti T, Olarte MBV, Agrawal PK, Jones CW. Acidcatalyzed conversion of sugars and furfurals in an ionic-liquid phase. Chemsuschem. 2009;2(7):665-71.

31. Cortez D, Roberto I, Barbosa M, Milagres A. Evaluation of cellulosic and hemicellulosic hydrolysate fermentability from sugarcane bagasse hybrids with different compositions. Biomass Conv Biorefin. 2014;4(4):351-6.

32. Turner MB, Spear SK, Huddleston JG, Holbrey JD, Rogers RD. Ionic liquid salt-induced inactivation and unfolding of cellulase from Trichoderma reesei. Green Chem. 2003:5:443-7.

33. Klein-Marcuschamer D, Simmons BA, Blanch HW. Techno-economic analysis of a lignocellulosic ethanol biorefinery with ionic liquid pretreatment. Biofuels Bioprod Biorefin. 2011;5(5):562-9.

34. Rajan K, Carrier DJ. Effect of dilute acid pretreatment conditions and washing on the production of inhibitors and on recovery of sugars during wheat straw enzymatic hydrolysis. Biomass Bioenerg. 2014;62:222-7.

35. Kumar R, Wyman CE. Access of cellulase to cellulose and lignin for poplar solids produced by leading pretreatment technologies. Biotechnol Progr. 2009;25:807-19.

36. Bals B, Rogers C, Jin MJ, Balan V, Dale B. Evaluation of ammonia fibre expansion (AFEX) pretreatment for enzymatic hydrolysis of switchgrass harvested in different seasons and locations. Biotechnol Biofuels. 2010:3:1-11.

37. Scullin C, Cruz AG, Chuang YD, Simmons BA, Loque D, Singh S. Restricting lignin and enhancing sugar deposition in secondary cell walls enhances monomeric sugar release after low temperature ionic liquid pretreatment. Biotechnol Biofuels. 2015;8:95-106.
38. Toquero C, Bolado S. Effect of four pretreatments on enzymatic hydrolysis and ethanol fermentation of wheat straw. Influence of inhibitors and washing. Bioresour Technol. 2014;157:68-76.

39. Labbe N, Rials TG, Kelley SS, Cheng ZM, Kim JY, Li Y. FT-IR imaging and pyrolysis-molecular beam mass spectrometry: new tools to investigate wood tissues. Wood Sci Technol. 2005;39(1):61-76.

40. Faix O. Classification of lignins from different botanical origins by FT-IR spectroscopy. Holzforschung. 1991;45(s1):21-8.

41. Siroky J, Blackburn RS, Bechtold T, Taylor J, White P. Attenuated total reflectance Fourier-transform infrared spectroscopy analysis of crystallinity changes in lyocell following continuous treatment with sodium hydroxide. Cellulose. 2010;17(1):103-15.

42. Morais ARC, Pinto JV, Nunes D, Roseiro LB, Oliveira MC, Fortunato E, et al. Imidazole: prospect solvent for lignocellulosic biomass fractionation and delignification. ACS Sus Chem Eng. 2016;4(3):1643-52.

43. Kuo CH, Lee CK. Enhancement of enzymatic saccharification of cellulose by cellulose dissolution pretreatments. Carbohyd Polym. 2009;77(1):41-6.

44. Zhang JF, Wang YX, Zhang LY, Zhang RH, Liu GQ, Cheng G. Understanding changes in cellulose crystalline structure of lignocellulosic biomass during ionic liquid pretreatment by XRD. Bioresour Technol. 2014;151:402-5.

45. Chundawat SP, Bellesia G, Uppugundla N, da Costa Sousa L, Gao $D$, Cheh AM, et al. Restructuring the crystalline cellulose hydrogen bond network enhances its depolymerization rate. J Am Chem Soc. 2011;133(29):11163-74

46. Wada M, Ike M, Tokuyasu K. Enzymatic hydrolysis of cellulose I is greatly accelerated via its conversion to the cellulose II hydrate form. Polym Degrad Stab. 2010;95(4):543-8.

47. Sun Y, Cheng JJ. Dilute acid pretreatment of rye straw and bermudagrass for ethanol production. Bioresour Technol. 2005:96(14):1599-606.

48. Zhang ZH, Zhao ZBK. Solid acid and microwave-assisted hydrolysis of cellulose in ionic liquid. Carbohydr Res. 2009;344(15):2069-72.

49. Yamaguchi D, Kitano M, Suganuma S, Nakajima K, Kato H, Hara M. Hydrolysis of cellulose by a solid acid catalyst under optimal reaction conditions. J Phys Chem C. 2009;113(8):3181-8.

50. Guo H, Lian Y, Yan L, Qi X, Smith RL. Cellulose-derived superparamagnetic carbonaceous solid acid catalyst for cellulose hydrolysis in an ionic liquid or aqueous reaction system. Green Chem. 2013;15(8):2167-74.

51. Larsson S, Palmqvist E, Hahn-Hägerdal B, Tengborg C, Stenberg K, Zacchi $\mathrm{G}$, et al. The generation of fermentation inhibitors during dilute acid hydrolysis of softwood. Enzyme Microb Technol. 1999:24(3):151-9.

52. Graves T, Narendranath NV, Dawson K, Power R. Effect of pH and lactic or acetic acid on ethanol productivity by Saccharomyces cerevisiae in corn mash. J Ind Microbiol Biot. 2006;33(6):469-74.

53. Horita M, Kitamoto H, Kawaide T, Tachibana Y, Shinozaki Y. On-farm solid state simultaneous saccharification and fermentation of whole crop forage rice in wrapped round bale for ethanol production. Biotechnol Biofuels. 2015:8:9-18.

54. Shill K, Padmanabhan S, Xin Q, Prausnitz JM, Clark DS, Blanch HW. Ionic liquid pretreatment of cellulosic biomass: enzymatic hydrolysis and ionic liquid recycle. Biotechnol Bioeng. 2011;108(3):511-20.

55. Sluiter A, Hames B, Ruiz R, Scarlata C, Sluiter J, Templeton D et al. Determination of structural carbohydrates and lignin in biomass. National Renewable Energy Laboratory, Golden CO. 2008; Technical Report NREL/ TP-510-42618.

56. Sluiter A, Hames B, Ruiz R, Scarlata C, Sluiter J, Templeton D. Determination of ash in biomass. National Renewable Energy Laboratory, Golden CO. 2008; Technical Report NREL/TP-510-42622.

57. Segal L, Creely J, Martin A, Conrad C. An empirical method for estimating the degree of crystallinity of native cellulose using the $\mathrm{X}$-ray diffractometer. Text Res J. 1959:29(10):786-94.

58. Miller GL. Use of dinitrosalicylic acid reagent for determination of reducing sugar. Anal Chem. 1959;31(3):426-8. 